\title{
ESCOLHAS CONTÁBEIS NO RECONHECIMENTO DE JOINT VENTURES DE COMPANHIAS ABERTAS BRASILEIRAS: CONSOLIDAÇÃO PROPORCIONAL VERSUS MÉTODO DE EQUIVALÊNCIA PATRIMONIAL
}

\author{
ACCOUNTIG CHOICES IN CERTIFICATING JOINT VENTURES IN PUBLIC \\ BRAZILIAN COMPANIES: PROPORTIONATE CONSOLIDATIONS VERSUS \\ EQUIDITY METHOD
}

\author{
Gleison de Abreu Pontes \\ gleison.orientador@gmail.com \\ Universidade Federal de Uberlândia
}

Flaida Êmine de Souza

flaidaemine@yahoo.com.br

Universidade Federal de Uberlândia

\author{
Cristiano Camargo \\ camargo_cris@hotmail.com \\ Universidade Federal de Uberlândia \\ Sirlei Lemes
$\underline{\text { sirlemes@uol.com.br }}$
Universidade Federal de Uberlândia
}

RESUMO: Até 2012 as companhias abertas brasileiras que possuíam Joint Ventures podiam reconhecer seus investimentos pelo método da Consolidação Proporcional (CP) ou pelo Método de Equivalência Patrimonial (MEP). A partir de 2013, com a emissão da IFRS 11 - Joint Arrangements (adotada no Brasil mediante o CPC 19 - Negócios em Conjunto), estas empresas deverão reconhecer seus investimentos exclusivamente pelo MEP. Assim, o presente estudo pretendeu analisar se características das empresas poderiam justificar a escolha dos gestores em utilizar a CP ou o MEP, quando essa opção ainda era permitida. Por meio da técnica de regressão logística, constatou-se que apenas o nível de governança corporativa e o tamanho da companhia apresentaram indícios de influenciar a escolha dos gestores quanto ao método empregado no reconhecimento de Joint Ventures.

Palavras-chave: Escolhas Contábeis; Joint Ventures; Consolidação Proporcional; Método de Equivalência Patrimonial.

ABSTRACT: Until 2012, Brazilian public companies which had joint ventures could certificate their investments by the Proportionate Consolidation (CP) or by the Equity Method (EM). From 2013, with the issuance of IFRS 11 - Joint Arrangements (adopted in Brazil by CPC 19 - Together Business), these companies have to certificate their investments only through EM. Thus, this study aims to analyze whether the company characteristics could justify the managers' choice in using CP or EM, when this option was still allowed. Using the logistic regression, we stated that the insurance level and the company size showed evidence of influencing the managers' choice according to the method of certificating joint ventures.

Key-Words: Accounting choices; Joint Ventures; Proportionate Consolidation; Equidity Method.

Artigo recebido em: 23/08/2014 ; Aceito em: 06/04/2015

R. Cont. Ufba, Salvador-Ba, v. 9, n. 2, p. 52 - 67, mai-ago 2015 


\section{INTRODUÇÃO}

Em um cenário econômico, pautado pela concorrência e dinamismo dos negócios, as empresas objetivam garantir a participação no mercado ou expansão de suas atividades, quer seja em âmbito local ou internacional. No intuito de alcançar esses objetivos, tem se acentuado nos últimos anos a parceria entre empresas para a formação de Joint Ventures (GRAHAM; KING; MORRIL, 2001).

A finalidade das Joint Ventures é a troca de know-how entre as empresas, o compartilhamento de interesses e a atuação sinérgica das atividades comuns, com a particularidade de serem empreendimentos formados por entidades distintas e até mesmo de países de origens diferentes (DARROUGH; STOUGHTON, 1989).

Quanto à sua definição, para fins contábeis, a International Accounting Standard (IAS) 28 - Investments in Associates and Joint Ventures, que no Brasil equivale ao Pronunciamento Técnico 18 - Investimento em Coligada, em Controlada e em Empreendimento Controlado em Conjunto, o qual foi emitido pelo Comitê de Pronunciamentos Contábeis (CPC) - CPC 18 (2012, p. 2) -, esclarece que Joint Ventures ou Empreendimentos Controlados em Conjunto (ECC) corresponde a "um acordo conjunto por meio do qual as partes, que detêm o controle em conjunto do acordo contratual, têm direitos sobre os ativos líquidos desse acordo".

Com relação ao método de reconhecimento de ECC, os órgãos normatizadores internacionais como o Financial Accounting Standards Board (FASB) e o International Accounting Standards Board (IASB), até o ano de 2012, traziam em suas normas a opção de reconhecer esses investimentos por meio da Consolidação Proporcional - CP - ou pelo Método de Equivalência Patrimonial - MEP (MACKENZIE et al., 2013).

Machado (2011) aponta que a liberdade da escolha contábil em aplicar a CP ou o MEP no reconhecimento de ECC foi uma forma encontrada para minimizar os conflitos entre as empresas que adotavam as recomendações do FASB ou do IASB.

No entanto, a opção de adotar um ou outro método de reconhecimento desses investimentos distanciava-se da harmonização contábil proposta (LOURENÇO; CURTO, 2010), e a partir do Acordo de Norwalk em 2001, o FASB e o IASB têm dirigido esforços a fim de minimizar as opções de escolha quanto aos métodos de reconhecimento de ECC (LOURENÇO; CURTO, 2010; TUDOR; DRAGU, 2010).

Para permitir que as normas contábeis possam ser aplicáveis mundialmente (PENG; SMITH, 2010), o IASB emitiu em 2011 a IFRS 11 - Joint Arrangements, a qual foi recepcionada no Brasil de acordo com o CPC 19 - Negócios em Conjunto, alterando assim a IAS 28 e a IAS 31 - Interests in Joint Ventures (MACKENZIE et al., 2013).

Uma das principais alterações dessa norma foi a determinação para que as empresas que adotam as Normas Internacionais de Contabilidade - International Financial Reporting Standards (IFRS) - utilizem somente o MEP no reconhecimento de ECC, a partir dos exercícios iniciados em $1^{\circ}$ de janeiro de 2013 (DELIBERAÇÃO CVM Nº 694, 2012).

Adicionalmente, essa norma deliberou a respeito da separação entre os tipos de negócios em conjunto, que podem corresponder tanto a ECC, quanto a uma Operação em Conjunto (Joint Operation), cuja distinção entre ambos, ocorre conforme o direito e as

R. Cont. Ufba, Salvador-Ba, v. 9, n. 2, p. 52 - 67, mai-ago 2015 
obrigações do investidor sobre os ativos, passivos e o patrimônio líquido do investimento (CPC 19, 2012).

Assim, quando os investidores possuem direitos somente sobre o patrimônio líquido (PL) do negócio em conjunto, tem-se um ECC. Por outro lado, quando os investidores apresentam suas participações sobre os ativos e passivos relacionados ao negócio compartilhado, em consonância com o acordo contratual estabelecido entre as partes, o negócio corresponde a uma Operação em Conjunto (CPC 19, 2012).

No cenário brasileiro, Iudícibus et al. (2010) relataram que desde a Instrução CVM n 247 de 1996, o país já buscava um alinhamento das práticas contábeis brasileiras com as internacionais no reconhecimento de ECC. Porém, a opção existente consistia apenas no uso do método da CP, ao invés da escolha entre a CP e o MEP (IUBÍCIBUS et al., 2010).

Não obstante, após a adoção pelo Brasil das IFRS, por meio da Lei 11.638 de 2007, a CVM permitiu a contabilização desses investimentos por ambos os métodos - CP ou MEP -, cujo tratamento contábil foi normatizado pelo CPC 18 e CPC 19 - Investimento em Empreendimento Controlado em Conjunto, ainda como equivalência a IAS 31 (CPC 19, 2011).

Nesse contexto, depois da vigência da IFRS 11, o CPC 19 passou a denominar-se de Negócios em Conjunto, o qual alterou ainda o CPC 18, e determinou que as companhias abertas brasileiras também reconhecessem os seus ECC a partir de 2013, utilizando somente o MEP (CPC 18, 2012; DELIBERAÇÃO CVM No 694, 2012).

Em se tratando das pesquisas desenvolvidas sobre ECC, estudos anteriores têm buscado demonstrar as razões que levaram as empresas a escolherem a CP ou o MEP em seus demonstrativos financeiros, e a relevância da informação na utilização desses métodos para os investidores. Contudo, alguns estudos encontraram resultados distintos quanto a essas escolhas e a sua influência sobre a tomada de decisão (BAUMAN, 2007; GRAHAM et al., 2001; LOURENÇO; CURTO, 2010; RICHARDSON et al., 2011).

Deste modo, segundo os resultados encontrados em estudos anteriores, e ainda, com base nas mudanças dos métodos de reconhecimento de investimentos em ECC, tendo como enfoque o contexto do Brasil, em que se permitia o uso de ambos os métodos, e atualmente restringe-se à utilização do MEP, a presente pesquisa se fundamentou no seguinte problema: quais as características apresentadas pelas companhias abertas brasileiras podem ter influenciado a escolha do método de reconhecimento de seus ECC, antes da obrigatoriedade de aplicação exclusiva do MEP?

Portanto, o presente estudo tem como objetivo analisar se algumas características relacionadas às companhias abertas brasileiras listadas na BM\&FBOVESPA influenciaram a escolha do método empregado por elas no reconhecimento de seus ECC.

Para alcançar esse objetivo, foram analisadas as 529 empresas listadas na bolsa de valores brasileira no período de 2012, que após passarem pelos critérios de análise definidos nesta pesquisa, resultou em 83 companhias abertas componentes da amostra final.

Como contribuição, espera-se que esta pesquisa amplie a base teórica relacionada às escolhas contábeis no que concerne ao reconhecimento de $\mathrm{ECC}$, pois de acordo com Francis (2001) essa temática é ampla, e carece de novos estudos que demonstrem os motivos que levam as empresas a tomarem as suas decisões quanto ao emprego de um determinado método contábil em seus relatórios financeiros.

R. Cont. Ufba, Salvador-Ba, v. 9, n. 2, p. 52 - 67, mai-ago 2015 
Assim, a identificação das características que determinam as escolhas contábeis, apontadas no estudo de Lorencini e Costa (2012), relacionadas às companhias brasileiras que possuem ECC, pode ajudar a explicar e a predizer as razões que influenciaram o método de reconhecimento escolhido por essas empresas, além de suprir a carência de estudos identificada no país sobre o tema (FURUTA; SANTOS, 2006).

Por fim, a caracterização das empresas que serão obrigadas a alterar o método contábil de reconhecimento dos ECC - de CP para MEP - permite a avaliação do impacto da nova norma e pode trazer contribuição para a discussão acerca da busca da comparabilidade pleiteada pelo IASB versus a representação fidedigna, partindo do pressuposto que a CP melhor representava a realidade das empresas (IUDÍCIBUS et al., 2010; RICHARDSON et al., 2011).

Este estudo encontra-se estruturado em cinco seções, além desta introdução. $\mathrm{Na}$ seção seguinte, é apresentada a discussão teórica utilizada no estudo. Na terceira seção são delineados os aspectos metodológicos empregados na pesquisa. Na quarta seção, tem-se a análise e a discussão dos resultados obtidos. Na última seção, as considerações finais do estudo são apresentadas.

\section{RECONHECIMENTO DE EMPREENDIMENTOS CONTROLADOS EM CONJUNTO}

De acordo com Lourenço e Curto (2010), o reconhecimento de ECC tem gerado dissenso internacional em órgãos normatizadores como o IASB, quanto ao melhor método a ser utilizado nesses investimentos. Graham et al. (2001) relatam que o tratamento contábil dos ECC tem ocorrido de maneira distinta entre os países, alternando a escolha entre a CP e o MEP.

Não obstante, Lourenço e Curto (2010) asseveram que o motivo dessa divergência consiste em haver poucos estudos sobre o tema, que relatem as razões que levam os gestores a escolherem a CP ou o MEP nos ECC (LOURENÇO; CURTO, 2010).

Richardson et al. (2011) mencionam também que os debates envolvendo os métodos de reconhecimento em ECC, se desenvolvem no sentido de compreender se os investidores realmente controlam o investimento e se eles seriam os responsáveis pelos respectivos passivos assumidos no negócio.

Lourenço e Curto (2010) ainda comentam que os opositores à CP, afirmam que os empreendedores não possuem controle sobre a parcela de ativos e passivos do negócio firmado em conjunto, portanto, o MEP seria o mais indicado para a contabilização desses investimentos.

Deste modo, o CPC 18 (2012) instiga a utilização do MEP nos ECC, ao deliberar que o interesse dos investidores é sobre o desempenho de suas investidas e, consequentemente sobre o retorno trazido por elas. Segundo o CPC $18(2012$, p. 4) "a aplicação do método da equivalência patrimonial proporciona relatórios com maior grau de informação acerca dos ativos líquidos do investidor e acerca de suas receitas e despesas".

No que se refere ao impacto da utilização dos métodos de reconhecimento nos relatórios financeiros, Lourenço e Curto (2010) e Richardson et al. (2011), apontam que a utilização de ambos os métodos resulta em uma variação considerável dos valores contábeis reportados pelas empresas em seus ECC, e que pela $\mathrm{CP}$, haveria o aumento dos

R. Cont. Ufba, Salvador-Ba, v. 9, n. 2, p. 52 - 67, mai-ago 2015 
ativos e passivos no balanço patrimonial das partes, por causa da parte proporcional que é refletida sobre os ECC.

A seguir, na Tabela 1, é apresentado um balanço patrimonial fictício sobre o efeito da aplicação da CP, considerando a existência de dois investimentos realizados por um investidor, ora denominado de Companhia A, que se referem às Companhias "B e C", as quais podem corresponder a uma coligada, controlada ou ECC, e que apresentaram como saldo de ativo e passivo, os valores de $\$ 8.000$ e $\$ 15.000$, respectivamente.

Tabela 1: Balanço patrimonial pelo método da $\mathbf{C P}$

\begin{tabular}{lccccc}
\hline Ativo & CIA A & CIA B (40\%) & CIA C (70\%) & Eliminaç̃̃es & Consolidado \\
\hline Banco & 0 & 80 & 560 & & 640 \\
Aplicação Financeira & 0 & 720 & 1.540 & & 2.260 \\
Estoque & 0 & 1.600 & 2.800 & & 4.400 \\
Investimento Cia B & 2.000 & 0 & 0 & -2.000 & 0 \\
Investimento Cia C & 7.000 & 0 & 0 & -7.000 & 0 \\
Imobilizado & 0 & 800 & 5.600 & & 6.400 \\
Total do Ativo & $\underline{9.000}$ & $\underline{3.200}$ & $\underline{10.500}$ & $\underline{-9.000}$ & $\underline{13.700}$ \\
\hline Passivo & $\underline{\text { CIA A }}$ & CIA B (40\%) & CIA C (70\%) & Eliminacões & Consolidado \\
\hline Fornecedores & 0 & 800 & 2.100 & & 2.900 \\
Empréstimos & 2.000 & 400 & 1.400 & & 3.800 \\
Patrimônio Líquido & $\underline{7.000}$ & $\underline{2.000}$ & $\underline{7.000}$ & $\underline{-9.000}$ & $\underline{7.000}$ \\
Capital & 5.000 & 1.600 & 4.900 & -6.500 & 5.000 \\
Reservas & 2.000 & 400 & 2.100 & -2.500 & 2.000 \\
Total do Passivo & $\underline{9.000}$ & $\underline{3.200}$ & $\underline{10.500}$ & $\underline{-9.000}$ & $\underline{13.700}$ \\
\hline
\end{tabular}

Fonte: Elaborado por Machado (2011, p. 11-12)

Na Tabela 1 é demonstrado que diante da existência de investimentos feitos por uma determinada companhia com o uso da $\mathrm{CP}$, essa incorreria em um aumento dos valores contábeis de seus ativos e passivos, por causa da aplicação desse método.

Furuta e Santos (2006) apontam que os defensores da CP, argumentam que a sua não utilização pelas partes controladoras do negócio, pode possibilitar o gerenciamento de resultados, uma vez que as empresas poderiam ocultar a existência de ativos e passivos, e dessa forma, apresentarem demonstrativos financeiros que favoreçam o acesso ao capital de terceiros.

Não obstante, a CVM recomendou no Brasil por meio da Resolução n ${ }^{\circ} 547$ de 2008, a divulgação de informações adicionais na Demonstração dos Fluxos de Caixa ao utilizar a CP, por entender que os investidores compreenderiam melhor a situação financeira das empresas (CVM, 2008).

Sob a óptica do MEP, o impacto sobre o balanço patrimonial do investidor, aconteceria somente por meio da variação dos investimentos ocorridos nos ECC (LOURENÇO; CURTO, 2010; RICHARDSON et al., 2011). Essa variação também pode ser observada em um balanço patrimonial fictício, a qual é demonstrada na Tabela 2.

Iudícibus et al. (2010, p. 174) explicam que pelo MEP, “o valor do investimento é determinado mediante a aplicação, sobre o valor de cada mutação do Patrimônio Líquido da investida, da percentagem de participação em seu capital".

Assim, com base nos dados da Tabela 2, e considerando uma situação hipotética, em que tenha ocorrido uma variação de $\$ 1.000$ no PL da Companhia B e de $\$ 3.000$ na Companhia $\mathrm{C}$, além de ter sido auferido pela Companhia A, zero de receitas e $\$ 500$ de 
despesas, verifica-se que, somente o valor dos investimentos mantidos pela Companhia A e o seu respectivo PL são alterados pelo MEP em seu balanço patrimonial.

Tabela 2: Balanço patrimonial utilizando o MEP

\begin{tabular}{lclc}
\hline Ativo CIA A & \multicolumn{3}{c}{ Passivo CIA A } \\
\hline Banco & 0 & Fornecedores & 0 \\
Aplicação Financeira & 0 & Empréstimos & 2.000 \\
Estoque & 0 & & \\
Investimento Cia B $(40 \%)$ & 2.000 & Patrimônio Líquido & $\underline{7.000}$ \\
Investimento Cia C $(70 \%)$ & 7.000 & Capital & 2.000 \\
Imobilizado & 0 & Reservas & 2.000 \\
Total do Ativo & $\underline{9.000}$ & Total do Passivo & $\underline{9.000}$ \\
\hline
\end{tabular}

Fonte: Elaborado por Machado (2011, p. 10)

Com relação à Demonstração do Resultado, Lourenço e Curto (2010) e Richardson et al. (2011), esclarecem ainda que as receitas e as despesas são reconhecidas pela CP, separadamente pelas partes investidoras na forma de um resultado operacional ao invés de financeiro, conforme pode ser observado na Tabela 3.

Tabela 3: Demonstração do resultado pela CP

\begin{tabular}{lccccc}
\hline & CIA A & CIA B (40\%) & CIA C (70\%) & Eliminacões & Consolidado \\
\hline Receitas & 0 & 2.000 & 8.400 & & 10.400 \\
(-) Custos & 0 & -1.200 & -4.900 & & -6.100 \\
(=) Lucro Bruto & 0 & 800 & 3.500 & -2.300 \\
(Desp. de Vendas e Adm.) & -500 & -400 & -1.400 & & 2.000 \\
Res. Equivalência Patrimonial & 2.500 & 0 & 0 & -2.500 & 0 \\
Resultado Antes dos Tributos & 2.000 & $\underline{400}$ & $\underline{2.100}$ & $\underline{-2.500}$ & $\underline{2.000}$ \\
\hline
\end{tabular}

Fonte: Elaborado com base em Machado (2011, p. 12)

Pode-se verificar que pela $\mathrm{CP}$, as receitas e as despesas das investidas são agrupadas aos respectivos valores contábeis do investidor (TABELA 3). Logo, pelo MEP, na demonstração de resultado tem-se uma receita de equivalência em caso de lucro, e uma despesa de equivalência em caso de prejuízo, os quais são apresentados nos resultados de cada uma das partes empreendedoras (LOURENÇO; CURTO, 2010; RICHARDSON et $a l ., 2011)$.

Porém, conforme é apresentado na Tabela 4, não existe diferenças significativas em relação aos valores contábeis reportados por ambos os métodos, quando comparado com o resultado apresentado antes dos tributos com a aplicação da CP ou do MEP.

Tabela 4: Demonstração de resultado pelo MEP

\begin{tabular}{lc}
\hline \multicolumn{2}{c}{ DRE da Companhia A } \\
\hline Receitas & 0 \\
(-) Custos & 0 \\
(=) Lucro Bruto & 0 \\
Despesas de Vendas e Administrativas & -500 \\
Resultado de Equivalência Patrimonial & 2.500 \\
Resultado Antes dos Tributos & $\underline{2.000}$ \\
\hline \multicolumn{2}{c}{ Fonte: Elaborado com base em Machado (2011, p. 10) }
\end{tabular}

A partir das diferenças evidenciadas nos métodos de reconhecimento, alguns estudos têm sido desenvolvidos no cenário internacional, para relatar os motivos que levaram as empresas a escolherem a $\mathrm{CP}$ ou o MEP nos $\mathrm{ECC}$, ou a pesquisas que 
demonstrem a relevância da informação no emprego desses métodos, enquanto essas opções estiveram disponíveis (BAUMAN, 2007; GRAHAM et al., 2001; LOURENÇO; CURTO, 2010; RICHARDSON et al., 2011).

Bauman (2007) constatou em seu estudo que, para a avaliação do risco de títulos pelas agências de classificação de crédito, as demonstrações financeiras das empresas de manufatura dos Estados Unidos que apresentaram maior relevância da informação, foram às companhias que empregaram o método da $\mathrm{CP}$.

Lourenço e Curto (2010) encontraram evidências em suas pesquisas, que as empresas do Reino Unido que estiveram mais propensas a utilização da $\mathrm{CP}$, foram aquelas que apresentaram alta alavancagem, e que o tipo de acordo firmado entre as partes - escala ou linha - influencia diretamente na definição do método empregado.

Assim, quando os ECC acontecem em escala, que é a estratégia de entrada em um novo mercado, visando à cooperação dos negócios, as empresas tendem a utilizar o MEP, uma vez que o acordo contratual proporciona maior proteção ao investimento realizado pelas partes (LOURENÇO; CURTO, 2010).

No entanto, quando o tipo do negócio é em linha, que compreende a atuação em setores distintos pelos empreendedores, essas companhias utilizariam a $\mathrm{CP}$, dado que esses ECC favorecem o dispêndio de recursos considerados críticos para um novo negócio. Além disso, esses autores afirmaram também que, as empresas tendem a utilizar a $\mathrm{CP}$, quando a maioria de seus ECC ocorre em linha (LOURENÇO; CURTO, 2010).

Quanto ao estudo de Richardson et al. (2011), encontrou-se que as empresas canadenses que utilizavam o MEP em seus ECC, experimentaram um declínio na relevância da informação dos seus ativos e passivos, quando essas empresas foram obrigadas a utilizar somente o método da CP.

Deste modo, esse estudo contrariou a pesquisa de Graham et al. (2001), a qual havia evidenciado que a utilização da $\mathrm{CP}$ forneceu informações mais relevantes para os investidores no cenário canadense do que pelo MEP, num contexto em que as empresas apresentaram maior compartilhamento de negócios em projetos de exploração e desenvolvimento.

No Brasil, Furuta e Santos (2006) motivados pelo argumento de que a não utilização da $\mathrm{CP}$ pelas partes controladoras do negócio em conjunto pode possibilitar o gerenciamento de resultados, trouxeram como resultado de seus estudos que, pelo método da CP os demonstrativos financeiros dos investidores apresentaram diferenças significativas nos valores reportados pelo balanço patrimonial quanto ao passivo circulante, exigível de longo prazo (nomenclatura atualizada para passivo não circulante) e sobre o índice de capital de terceiros sobre o capital próprio.

Logo, os investimentos na modalidade em conjunto têm apresentado crescimento significativo (MACHADO, 2011), e se faz necessário que novos estudos demonstrem o impacto da aplicação da $\mathrm{CP}$, ou outros métodos de reconhecimento utilizados pelas companhias abertas brasileiras (FURUTA; SANTOS, 2006).

\subsection{Escolhas Contábeis}

Segundo Fields, Lyz e Vicent (2001), as pesquisas em escolhas contábeis foram impulsionadas em 1960 pela criação dos Accounting Principles Board (ACP), que foi um

R. Cont. Ufba, Salvador-Ba, v. 9, n. 2, p. 52 - 67, mai-ago 2015 
órgão do American Institute of Certified Public Accountants (AICPA), o qual emitia princípios contábeis até 1973 nos Estados Unidos, e que foi substituído posteriormente pelo FASB.

No entanto, esses autores discutiram que apesar dos esforços dessas pesquisas desde a década de 60 , ainda não se tem uma definição clara sobre os propósitos que as escolhas contábeis atendem, já que diante dos Generally Accepted Accounting Principles ou Princípios Contábeis Geralmente Aceitos (PCGA) e da legislação vigente em cada país, os gestores ao realizarem as suas escolhas podem prezar pelos interesses dos proprietários da empresa, ou aos seus próprios interesses (FIELDS et al., 2001).

Fields et al. (2001, p. 256) trazem também uma definição que julgaram ampla para a definição de escolhas contábeis, que corresponde a:

qualquer decisão, cujo objetivo principal é influenciar (seja na forma ou substância), a saída do sistema de contabilidade de uma forma particular, incluindo não apenas as demonstrações financeiras publicadas de acordo com o GAAP, mas também declarações fiscais e arquivamentos regulatórios.

Watts (1992) definiu que as escolhas contábeis correspondem à decisão de um gestor pela utilização de um método contábil em oposição a outro, afirmando, porém, que é necessário conhecer as razões que levaram àquelas escolhas contábeis. Lopes e Iudícibus (2004) comentam também que a busca pela compreensão de como as empresas decidem sobre o tipo de informação que devem divulgar, impulsionou a corrente de pesquisa que originou a Teoria Positiva da Contabilidade na década de 80, cujo enfoque é explicar e predizer os fenômenos contábeis.

As escolhas contábeis podem ainda afetar a situação econômico-financeira de uma empresa, mesmo que essa escolha represente fidedignamente um fenômeno econômico, de acordo com as IFRS (BARTH et al., 2008; CPC 00, 2011).

Em razão da discricionariedade permitida por essas normas, algumas escolhas podem levar à prática de gerenciamento de resultados, que para Lo (2008), consiste na utilização de julgamentos para influenciar ou enganar os stakeholders.

Nesse sentido, Fields et al. (2001) defendem que os órgãos reguladores precisariam compreender quais são os benefícios de se permitir escolhas contábeis, e qual o nível de discrição inerente a cada uma delas. Porém, Barth et al. (2008), afirmam que a qualidade da informação contábil seria melhorada se os órgãos normatizadores reduzissem o número de escolhas previstas nos PCGA.

Francis (2001) criticou os resultados apresentados pelos estudos de Fields et al. (2001), em virtude de esses autores terem simplesmente categorizado as pesquisas desenvolvidas em escolhas contábeis, sem, no entanto, avaliar as motivações que levaram aos resultados apresentados pelos estudos, as características dos projetos de pesquisa desenvolvidos e a facilidade na obtenção dos dados para a realização de pesquisas, o que na visão dele, proporcionaria o desenvolvimento de novos estudos que contribuíssem para a expansão dessa temática (FRANCIS, 2001).

Além dos trabalhos que abordam a influência do gestor relativo às escolhas contábeis na utilização de um método contábil (WATTS, 1992), ou ainda, a interferência dos órgãos reguladores acerca das escolhas contábeis (FIELDS et al., 2001; BARTH et al., 2008), Lorencini e Costa (2012) relacionaram alguns fatores como o nível de governança

R. Cont. Ufba, Salvador-Ba, v. 9, n. 2, p. 52 - 67, mai-ago 2015 
corporativa, a influência de auditoria por Big Four, participação dos administradores nos lucros, emissão de American Depositary Receipt (ADR), tamanho do ativo diferido, reavaliação de bens do ativo imobilizado e endividamento, como determinantes das escolhas contábeis. A partir dessas variáveis, os autores encontraram que apenas o nível de governança corporativa e o saldo do ativo diferido influenciaram as escolhas contábeis das empresas brasileiras pesquisadas.

O Quadro 1 apresenta a síntese dos fatores trazidos pelo estudo de Lorencini e Costa (2012):

Quadro 1: Determinantes das escolhas contábeis segundo Lorencini e Costa (2012)

\begin{tabular}{|c|c|}
\hline Variáveis & Pressupostos para a Escolha Contábil \\
\hline $\begin{array}{l}\text { Nível de } \\
\text { Governança } \\
\text { Corporativa }\end{array}$ & $\begin{array}{l}\text { Empresas que adotam essa forma de gestão tendem a possibilitar uma maior } \\
\text { comparabilidade de seus relatórios financeiros com os relatórios apresentados pelas } \\
\text { empresas estrangeiras. Dessa forma, a escolha contábil estaria relacionada com o } \\
\text { nível de governança apresentado pelas empresas. }\end{array}$ \\
\hline $\begin{array}{l}\text { Auditoria por } \\
\text { Big Four }\end{array}$ & $\begin{array}{l}\text { Espera-se que uma companhia auditada por firmas de auditoria Big Four como a } \\
\text { Deloitte Touche Tohmatsu, Ernst \& Young, KPMG ou PricewaterhouseCoopers, } \\
\text { incorra em menores índices de gerenciamento de resultados. Portanto, os relatórios } \\
\text { financeiros apresentados por essas companhias, seriam influenciados pela presença } \\
\text { das firmas de auditoria. }\end{array}$ \\
\hline $\begin{array}{c}\text { Participação dos } \\
\text { Administradores } \\
\text { nos Lucros } \\
\end{array}$ & $\begin{array}{l}\text { Alguns estudos evidenciaram que os gestores possuem incentivos para aumentarem } \\
\text { os resultados que são reportados nos demonstrativos financeiros, quando a sua } \\
\text { remuneração depende desses resultados. }\end{array}$ \\
\hline $\begin{array}{c}\text { Emissão de } \\
\text { American } \\
\text { Depositary } \\
\text { Receipt (ADR) }\end{array}$ & $\begin{array}{l}\text { Os estudos relatados pelos autores trazem que os PCGA dos Estados Unidos não } \\
\text { permitem o reconhecimento de ativos diferidos, dessa forma, as companhias que } \\
\text { negociam suas ações no mercado americano, tenderiam a baixar esses ativos. } \\
\text { No quesito gerenciamento de resultados, não se encontrou diferenças entre as } \\
\text { empresas emissoras e as não emissoras de ADR. }\end{array}$ \\
\hline $\begin{array}{c}\text { Tamanho do } \\
\text { Ativo Diferido }\end{array}$ & $\begin{array}{l}\text { Esse fator pressupõe que as empresas detentoras de altos valores registrados em seu } \\
\text { ativo diferido fariam a escolha contábil pela sua manutenção, e que o tamanho da } \\
\text { empresa é levado em consideração quando ocorre a sua baixa. }\end{array}$ \\
\hline $\begin{array}{l}\text { Reavaliação de } \\
\text { Bens do Ativo } \\
\text { Imobilizado }\end{array}$ & $\begin{array}{l}\text { Um dos estudos citados pelos autores mostrou que as empresas que não fazem a } \\
\text { reavaliação, apresentaram melhores índices econômico-financeiros, e que um estudo } \\
\text { realizado no Brasil atribuiu a reavaliação como uma prática que recebe incentivos } \\
\text { gerenciais. Cabe ressaltar que essa opção não está disponível no cenário brasileiro. }\end{array}$ \\
\hline Endividamento & $\begin{array}{l}\text { Os estudos apontados quanto a esse fator, relacionam endividamento e covenants } \\
\text { contratuais. Outros autores que foram mencionados nesse determinante da escolha } \\
\text { contábil relataram que as empresas com maior grau de endividamento, dispõem de } \\
\text { incentivos para a escolha de determinados métodos contábeis. }\end{array}$ \\
\hline
\end{tabular}

Fonte: Elaborado com base em Lorencini e Costa (2012).

Deste modo, o presente estudo contribui para o tema sobre escolhas contábeis, ao analisar se algumas características das companhias abertas brasileiras listadas na BM\&FBOVESPA influenciaram a escolha do método empregado por elas no reconhecimento de seus ECC. Para isso, descreve-se a seguir, a metodologia empregada no seu desenvolvimento.

\section{ASPECTOS METODOLÓGICOS}

Este estudo pode ser compreendido como uma pesquisa descritiva e documental (GIL, 2006). Com relação a sua abordagem, trata-se de uma pesquisa quantitativa, uma vez 
que, por meio de técnicas estatísticas, buscou-se relacionar características das empresas que pudessem ter influenciado a escolha dos gestores pela utilização da CP ou do MEP.

Para a coleta de dados, foi acessada a página da BM\&FBOVESPA, e para a definição da amostra foi verificado se as empresas listadas participavam em algum nível de governança corporativa, que a sua atividade principal não se restringe a participação em outras sociedades, não pertencessem ao setor financeiro e não apresentassem Brazilian Depositary Receipts (BDRs). Atendido a esses critérios, foram selecionadas somente as companhias listadas na bolsa de valores brasileira que apresentassem ECC (APÊNDICE A). Na sequência foram analisadas suas notas explicativas, pareceres dos auditores e as demonstrações contábeis de 2012, por corresponder ao último exercício social em que as companhias abertas poderiam utilizar o método da CP ou o MEP. A Tabela 5 apresenta a quantidade de empresas selecionadas e que compuseram a amostra final do estudo:

Tabela 5: Composição da amostra do estudo

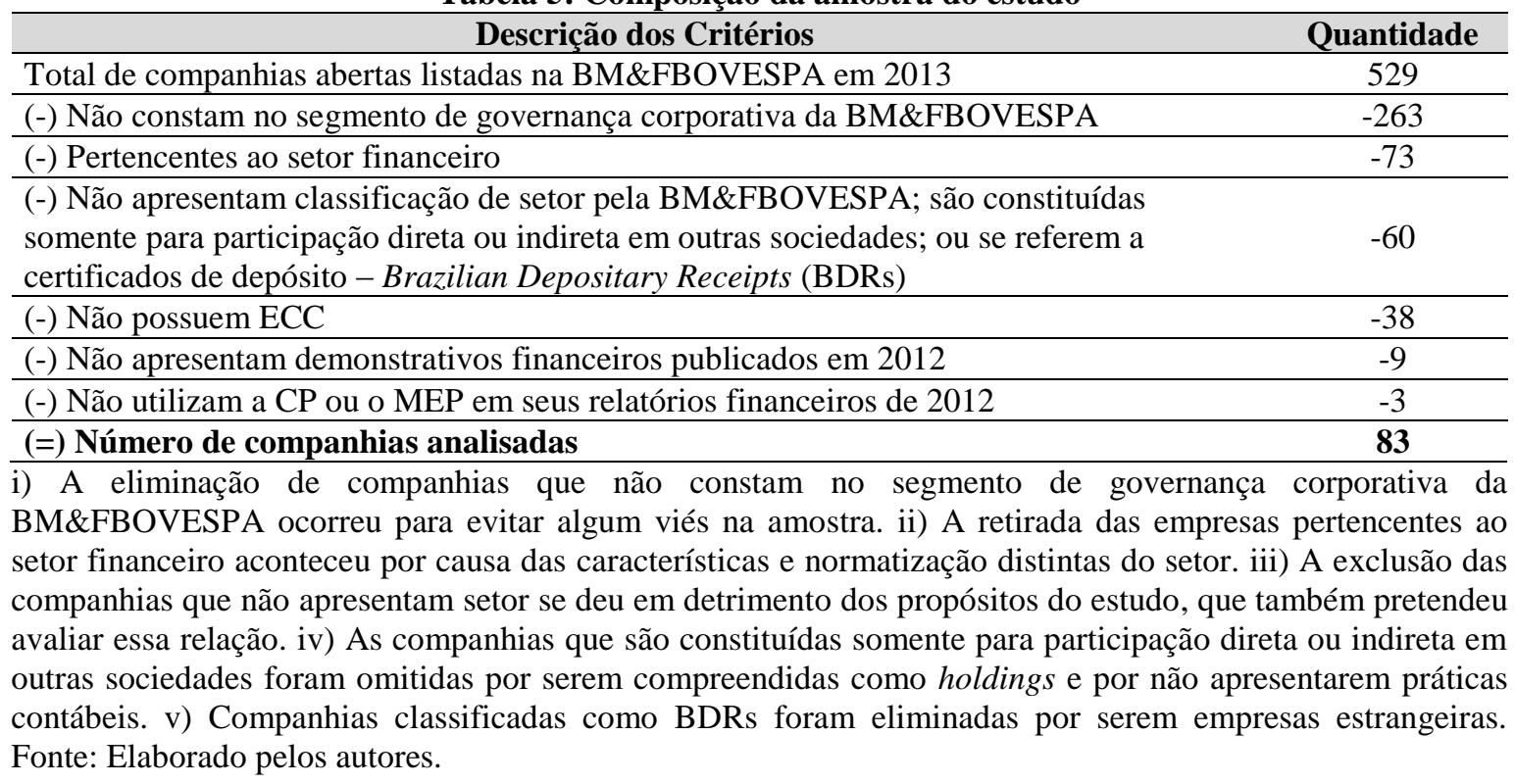

Para a análise das características das entidades que pudessem ter influenciado a escolha dos gestores pelo método da $\mathrm{CP}$ ou do MEP, utilizou-se dos fatores previstos no estudo de Lorencini e Costa (2012), cujas variáveis selecionadas foram as seguintes: nível de governança corporativa, auditoria por Big Four, participação dos administradores nos lucros, endividamento e tamanho da companhia.

As variáveis relacionadas à reavaliação e ao tamanho do ativo diferido foram excluídas por corresponderem a itens que não são permitidos pela legislação brasileira. A variável relativa à emissão de ADR não foi utilizada, em razão de as entidades que compuseram a amostra final, não emitirem tais papeis.

Entendeu-se oportuno acrescentar a variável setor de atuação, pelo pressuposto de que as empresas que operam em circunstâncias semelhantes tendem a adotar os mesmos métodos contábeis para fatos semelhantes (JAAFAR; MCLEAY, 2007). No Quadro 2 é apresentado um resumo das variáveis analisadas:

Quadro 2: Variáveis do modelo

\begin{tabular}{|l|l|l|}
\hline Variável & Nome & Proxy \\
\hline
\end{tabular}

R. Cont. Ufba, Salvador-Ba, v. 9, n. 2, p. 52 - 67, mai-ago 2015 


\begin{tabular}{|c|c|l|}
\hline EC & Escolha Contábil & Variável dummy: 0=CP; 1=MEP. \\
\hline SET & Setor de Atuação & $\begin{array}{l}\text { Uma variável dummy para cada setor: 1=bens industriais; } \\
\text { 2=construção e transporte; 3=consumo cíclico; 4=consumo não } \\
\text { 7=tecnologia da informaçãa; } 8=\text { =telecomunicomicações; e 9=utilidade } \\
\text { pública. }\end{array}$ \\
\hline NGC & $\begin{array}{c}\text { Nível de Governança } \\
\text { Corporativa }\end{array}$ & $\begin{array}{l}\text { Uma variável } \text { dummy para cada setor: 0=Mercado de Balcão; } \\
\text { 1=Bovespa Mais; 2=Nível 1; 3=Nível 2; e 4 = Novo Mercado. }\end{array}$ \\
\hline BF & Auditoria por Big Four & $\begin{array}{l}\text { Variável } \text { dummy: 0=não auditada por big four; 1=auditada por } \\
\text { big four. }\end{array}$ \\
\hline PAL & $\begin{array}{c}\text { Participação dos } \\
\text { Administradores nos } \\
\text { Lucros }\end{array}$ & Variável dummy: 0=não participa; 1=participa. \\
\hline ENDIV & Endividamento & Relação entre a dívida total e o ativo total. \\
\hline TPL & Tamanho da empresa & Medido pelo logaritmo natural do patrimônio líquido. \\
\hline
\end{tabular}

Fonte: Adaptado de Lorencini e Costa (2012).

Posto que a variável dependente (ECC) comporta apenas dois valores, tornou-se necessário a utilização de modelos de escolha qualitativa binária, como o modelo Logit e Probit. De acordo com Gujarati (2004), embora os dois modelos sejam semelhantes em grande parte de suas aplicações e os pesquisadores, em sua maioria, escolherem o modelo Logit em virtude de sua simplicidade comparativa, há situações em que o modelo Probit pode ser adeuqado. Assim, optou-se por realizar testes estatísticos (teste qui-quadrado), a fim de se avaliar qual dos dois modelos melhor se adequaria aos dados desta pesquisa. $\mathrm{O}$ modelo Probit foi considerado o melhor modelo para a estimação da regressão, portanto, foi o modelo utilizado nessa pesquisa.

A estrutura geral dos modelos de escolha qualitativa binária é baseada em probabilidades, e sua ideia geral está representada pela Equação 1, proposta por Johnston e DiNardo (2001):

$$
\operatorname{Prob}\left(\mathrm{Y}_{\mathrm{i}}=1\right)=\mathrm{F}(\mathrm{X} \beta)
$$

Onde, Y é a escolha das companhias abertas brasileiras, sendo igual a 0 caso a opção exercida seja a $\mathrm{CP}$, e 1 caso seja o MEP. X representa a matriz de variáveis independentes elencadas no Quadro 2: SET, NGC, BF, PAL, ENDIV e TPL. $\beta$ reflete o impacto das mudanças em X, na probabilidade de uma entidade optar pelo MEP. $F$ é a função de distribuição logística que altera o modelo adequado $X \beta$, em um intervalo entre 0 e 1 .

Assim, na Equação 2, encontra-se demonstrado o modelo de regressão logística utilizado neste estudo, em que as variáveis contidas no Quadro 2 foram utilizadas:

$$
\mathrm{EC}_{\mathrm{i}}=\beta_{0}+\beta_{1} \mathrm{SET}_{\mathrm{i}}+\beta_{2} \mathrm{NGC}_{\mathrm{i}}+\beta_{3} \mathrm{BF}_{\mathrm{i}}+\beta_{4} \mathrm{PAL}_{\mathrm{i}}+\beta_{5} \mathrm{ENDIV}_{\mathrm{i}}+\beta_{6} \mathrm{TPL}_{\mathrm{i}}+\varepsilon_{\mathrm{i}}
$$

Buscou-se interpretar os resultados da regressão logística por meio dos efeitos marginais, por permitirem avaliar o impacto na probabilidade das entidades optarem pelo MEP, em decorrência de alterações nas variáveis independentes. Ilustrar apenas os coeficientes da regressão não é útil, a não ser que se deseje analisar apenas o seu sinal e a sua significância (HOSMER; LEMESHOW, 2000). 
Os ajustes do modelo foram avaliados por meio de três testes: (a) o teste HosmerLemeshow, para verificar se existem diferenças significativas entre as frequências observadas e as frequências previstas; (b) a tabela de classificação, a fim de examinar o percentual de acerto do modelo e as medidas de sensitividade e especificidade; e (c) a curva Receiver Operating Characteristic (ROC), com a finalidade de mensurar a capacidade do modelo em discriminar as categorias da variável dependente (EC).

A seguir, os resultados da pesquisa são expostos, discutindo se algumas características relacionadas às companhias abertas brasileiras influenciaram a escolha do método empregado por elas no reconhecimento de seus ECC.

\section{RESULTADOS E DISCUSSÕES}

Conforme mencionado na seção anterior, após a triagem das 529 empresas que possuem ECC, a amostra final da pesquisa foi composta por 83 companhias abertas brasileiras. Na Tabela 6, essas empresas são evidenciadas segundo a escolha contábil apresentada em seus demonstrativos contábeis no ano de 2012.

\begin{tabular}{ccc} 
Tabela 6: Companhias pesquisadas e escolha contábil \\
\hline CP & MEP & Total \\
\hline 45 & 38 & 83 \\
$54,21 \%$ & $45,79 \%$ & $100 \%$ \\
\hline
\end{tabular}

Pode-se verificar com base nos dados da Tabela 6, que as companhias pesquisadas apresentaram em sua maioria a escolha pela CP $(54,11 \%)$ em relação ao MEP $(45,89 \%)$. Esses resultados mostram o impacto que a adoção da IFRS 11 provocou no Brasil, no ano de 2013, pois fez com que mais da metade das companhias brasileiras selecionadas migrassem para o MEP.

Com relação ao emprego das técnicas estatísticas, para averiguar se existia a necessidade de transformar os dados das variáveis TPL e ENDIV, foi aplicada a técnica ladder, e verificou-se que tanto a variável TPL quanto a variável ENDIV precisariam ser transformadas. Após a transformação das variáveis $\left(\mathrm{TPL}=1 /\left(\mathrm{tpl} \mathrm{l}^{\wedge} 3\right)\right.$ e ENDIV=(1/sqrt(endiv) $)$, partiu-se para a análise da regressão, cujo dados estão resumidos na Tabela 7.

Tabela 7: Resumo do modelo probit com efeitos marginais

\begin{tabular}{lcccc}
\hline \multicolumn{1}{c}{ EC } & Efeitos Marginais & Desvio Padrão & $\mathbf{Z}$ & $\mathbf{P}>|\mathbf{Z}|$ \\
\hline SET2 & -0.0069 & 0.1868 & -0.0400 & 0.9700 \\
SET3 & -0.1925 & 0.2138 & -0.9000 & 0.3680 \\
SET4 & 0.2273 & 0.2419 & 0.9400 & 0.3470 \\
SET5 & 0.3705 & 0.2537 & 1.4600 & 0.1440 \\
SET7 & -0.1873 & 0.3646 & -0.5100 & 0.6070 \\
SET8 & 0.2023 & 0.3763 & 0.5400 & 0.5910 \\
SET9 & -0.2580 & 0.1987 & -1.3000 & 0.1940 \\
NGC1 & -0.3658 & 0.2256 & -1.6200 & $0.1050^{*}$ \\
NGC2 & -0.0517 & 0.2736 & -0.1900 & 0.8500 \\
NGC3 & 0.1525 & 0.2440 & 0.6200 & 0.5320 \\
NGC4 & -0.1300 & 0.1828 & -0.7100 & 0.4770 \\
BF & 0.1764 & 0.2177 & 0.8100 & 0.4180 \\
TPL & 1357.4650 & 695.2902 & 1.9500 & $0.0510^{* *}$ \\
ENDIV & 0.0712 & 0.2740 & 0.2600 & 0.7950
\end{tabular}

R. Cont. Ufba, Salvador-Ba, v. 9, n. 2, p. 52 - 67, mai-ago 2015 
$\begin{array}{lc}\text { Prob }>\text { chi2 } & 0.1971 \\ \text { Pseudo R2 } & 0.1508 \\ \text { Hosmer-Lemeshow (HL) } & \mathbf{7 5 . 4 8} \\ \text { Prob }>\text { HL } & \mathbf{0 . 1 3 4 7}\end{array}$

SET é a dummy por setor, sendo: SET2 Construção e Transporte, SET3 Consumo Cíclico, SET4 Consumo não Cíclico, SET5 Materiais Básicos, SET7 Tecnologia da Informação, SET8 Telecomunicações e SET9 Utilidade Pública. O setor de petróleo, gás e biocombustíveis inicialmente elencados (SET6) não apresentou coeficiente. NGC é a dummy de níveis de governança corporativa, em que: NGC1 Bovespa Mais, NGC2 Nível 1; NGC3 Nível 2; NGC4 Novo Mercado. BF é a dummy de big four, TPL é o tamanho da entidade e ENDIV é o endividamento da empresa. Significância estatística: * $\mathrm{p}<0.1, * * \mathrm{p}<0.05, * * * \mathrm{p}<0.01$.

Quanto à verificação se o setor de atuação da companhia interfere na escolha do método de reconhecimento de ECC, tem-se que os parâmetros do setor de petróleo, gás e biocombustíveis (SET6) não foram estimados, em virtude de apenas uma entidade desse setor compor a amostra. Essa companhia optou pelo método da $\mathrm{CP}$.

Em relação aos setores de atuação com parâmetros estimados, percebe-se que nenhum setor apresentou indicadores significativos. Em outras palavras, o fato de a empresa pertencer a um determinado setor de atuação não influencia as decisões dos gestores, ou seja, não aumenta e nem diminui a probabilidade de que ela opte pelo MEP.

No que diz respeito aos níveis de governança corporativa, apenas o Bovespa Mais (NGC1) trouxe indícios de influenciar as decisões dos gestores quanto ao reconhecimento de investimentos. A um nível nominal de significância de $10 \%$, o fato de a entidade pertencer ao Bovespa Mais, reduz em 36,58\% a probabilidade de que ela escolha o MEP.

Pelo fato de apenas três entidades não remunerarem seus gestores por meio de participação nos lucros, a variável PAL foi omitida pelo software stata ${ }^{\circledR}$ e, portanto, também não obteve seus indicadores aferidos.

Ao se observar se as variáveis: big four, tamanho da empresa e endividamento interferem nas decisões dos gestores, constatou-se que apenas o tamanho da companhia apresentou resultados estatisticamente significativos. Isso denota que: a um nível nominal de significância de 5\%, há indícios de que o tamanho do ativo aumenta consideravelmente a probabilidade de a entidade optar pelo MEP ao reconhecer seus investimentos.

Assim, não se pode inferir que o endividamento influenciou a escolha pela $\mathrm{CP}$ no cenário brasileiro, diferentemente dos resultados encontrados no estudo de Lourenço e Curto (2010) para as empresas do Reino Unido.

Com a finalidade de examinar se existe associação entre os valores observados e estimados, foi realizado o Teste de Hosmer-Lemeshow, em que se constatou que: ao nível nominal de significância de 5\%, verifica-se que existe associação entre os valores observados e previstos, ou seja, o modelo probit, proposto na Tabela 7, possui um bom ajuste (p-valor>0.05). Partindo-se para a verificação do percentual de acerto do modelo aplicado, foi feita a tabela de classificação do modelo, como demonstrado na Tabela 8.

Tabela 8: Classificação do modelo

\begin{tabular}{|c|c|c|c|c|}
\hline \multirow{2}{*}{ OBSERVADO $^{d}$} & \multicolumn{3}{|c|}{ Reconhecimento de Investimentos } & \multirow[b]{2}{*}{ \% Correta } \\
\hline & Valor Justo (+) & Custo (-) & Total & \\
\hline $\mathrm{MEP}=1$ & 19 & 10 & 29 & $55.88^{\mathrm{a}}$ \\
\hline $\mathrm{CP}=0$ & 15 & 34 & 49 & $77.27^{\mathrm{b}}$ \\
\hline Total & 34 & 44 & 78 & $67.95^{\mathrm{c}}$ \\
\hline
\end{tabular}

a. sensitividade; b. especificidade; c. percentual de acerto do modelo. Ponto de corte $=0.50$.

R. Cont. Ufba, Salvador-Ba, v. 9, n. 2, p. 52 - 67, mai-ago 2015 
Quanto à sensitividade, que mede o total de acertos que o modelo tem em relação à escolha do MEP (evento de interesse), tem-se que o modelo classificou corretamente $55.88 \%$ das entidades que optaram por esse método. Todavia, no que tange à especificidade, que se refere ao total de acertos que o modelo tem em relação ao não evento de interesse (escolha do gestor em reconhecer seus investimentos pela $\mathrm{CP}$ ), extraise que o modelo classificou corretamente $77.27 \%$ das entidades que optaram pela CP. Em consequência, tem-se que, de um modo geral, o modelo logístico utilizado conseguiu classificar corretamente $67.95 \%$ das observações analisadas.

Enfim, visando mensurar o poder discricionário do modelo, calculou-se a curva ROC, cuja área foi 0.7453. Portanto, posto que a área da curva possui valor ente 0.7 e 0.8 , pode-se inferir que o modelo em questão apresenta um poder discricionário aceitável (HOSMER; LEMESHOW, 2000).

\section{CONSIDERAÇÕES FINAIS}

Este estudo objetivou analisar se as características das companhias abertas brasileiras listadas na BM\&FBOVESPA influenciaram a escolha do método empregado por elas no reconhecimento de seus ECC, antes da mudança da norma, quando ainda era possível escolher entre a $\mathrm{CP}$ e o MEP.

Por meio de uma análise documental, foram analisadas as notas explicativas, os pareceres dos auditores e as demonstrações contábeis, referente a 83 companhias abertas listadas na bolsa de valores brasileira, no ano de 2012.

Após a coleta dos dados, esses foram analisados sob a óptica de algumas variáveis previstas no estudo de Lorencini e Costa (2012), tais como: o nível de governança corporativa, auditoria por Big Four, participação dos administradores nos lucros, endividamento, tamanho da companhia e, como variável adicional, o setor de atuação. Assim, esse trabalho contribui com a literatura científica sobre escolhas contábeis, ao tentar elucidar as possíveis razões que levaram as companhias abertas brasileiras a utilizarem a $\mathrm{CP}$ ou $\mathrm{MEP}$, quanto ao reconhecimento de seus investimentos, quando essa escolha ainda era permitida pelo CPC e pela CVM.

Os resultados da pesquisa mostram que houve uma relativa predominância pela escolha da CP no ano de 2012, em que 54,11\% das empresas optaram pela utilização deste método, frente a 45,89\% que utilizaram o MEP. Esses percentuais delineiam o impacto que a adoção da IFRS 11 teve para as companhias abertas selecionadas no ano seguinte de 2012, com mais da metade das empresas tendo de alterar a sua prática contábil no reconhecimento de ECC. O Quadro 3 apresenta o resumo das variáveis testadas neste estudo e os resultados encontrados.

Quadro 3: Variáveis testadas e resultados encontrados

\begin{tabular}{|c|c|c|c|}
\hline Variável & Resultado & Aplicabilidade & Método \\
\hline Setor de Atuação & Não apresentou influência & - & - \\
\hline $\begin{array}{c}\text { Nível de Governança } \\
\text { Corporativa }\end{array}$ & $\begin{array}{c}\text { Indícios de influência sobre a } \\
\text { escolha }\end{array}$ & Bovespa Mais & CP \\
\hline $\begin{array}{c}\text { Auditoria por Big } \\
\text { Four }\end{array}$ & Não apresentou influência & - & - \\
\hline $\begin{array}{c}\text { Participação dos } \\
\text { Administradores nos } \\
\text { lucros }\end{array}$ & Não apresentou influência & - & - \\
\hline
\end{tabular}

R. Cont. Ufba, Salvador-Ba, v. 9, n. 2, p. 52 - 67, mai-ago 2015 


\begin{tabular}{|c|c|c|c|}
\hline Endividamento & Não apresentou influência & - & - \\
\hline Tamanho da empresa & $\begin{array}{c}\text { Indícios de influência sobre a } \\
\text { escolha }\end{array}$ & Maior Patrimônio Líquido & MEP \\
\hline
\end{tabular}

Não obstante, essa pesquisa avançou em relação ao estudo de Lorencini e Costa (2012) ao revelar, por meio dos testes estatísticos, que, a participação em algum dos níveis de governança corporativa e o tamanho da companhia podem ser considerados como indicadores das escolhas contábeis pelas companhias brasileiras. Ademais, avançou em relação àquela pesquisa ao constatar que o setor de atuação não interfere na escolha contábil dos gestores das empresas da amostra em relação ao reconhecimento de ECC.

Cabe salientar, contudo, que os resultados deste trabalho foram tratados como indícios, em virtude do número limitado de entidades analisadas. Sugere-se para futuras pesquisas, que se analisem as escolhas contábeis referentes ao reconhecimento de investimentos de todas as companhias abertas brasileiras, para o período de 2012, a fim de confirmar os resultados aqui encontrados. Recomenda-se, também, o estudo da relevância da informação dos demonstrativos contábeis publicados em 2013, quando as companhias abertas brasileiras foram obrigadas a utilizar somente o MEP no reconhecimento de ECC.

\section{REFERÊNCIAS}

BARTH, M. E.; LANDSMAN, W.; LANG, M. H. International accounting standards and accounting quality. Journal of Accounting Research, v. 46, n. 3, p. 467-498, 2008.

BAUMAN, M. P. Proportionate consolidation versus the equity method: additional evidence on the association with bond ratings. International Review of Financial Analysis, v. 16, n. 5, p. 496-507, 2007.

COMISSÃO DE VALORES MOBILIÁRIOS. Deliberação CVM nº 694, de 23 de novembro de 2012. Diário Oficial da República Federativa do Brasil, Brasília, DF, 23 nov. 2012. Disponível em: <http://www.cvm.gov.br/asp/cvmwww/atos/Atos_Redir.asp?Tipo=D\&File=ldelildeli694.d oc>. Acesso em: 22 jan. 2014.

COMISSÃO DE VALORES MOBILIÁRIOS. Deliberação CVM n ${ }^{\circ}$ 547, de 13 de agosto de 2008. Diário Oficial da República Federativa do Brasil, Brasília, DF, 13 ago. 2008. Disponível em: <http://www.cvm.gov.br/port/infos/deli547.pdf>. Acesso em: $09 \mathrm{dez}$. 2013.

COMITÊ DE PRONUNCIAMENTOS CONTÁBEIS. Pronunciamento conceitual básico

(R1): estrutura conceitual para elaboração e divulgação de relatório contábil-financeiro. 2011. Disponível em: 〈http://www.cpc.org.br/pronunciamentosIndex.php〉. Acesso em: 01 dez. 2013.

COMITÊ DE PRONUNCIAMENTOS CONTÁBEIS. Pronunciamento Técnico CPC 18 (R2): investimento em coligada e em empreendimento controlado em conjunto. 2012. Disponível em: <http://www.cpc.org.br/pronunciamentosIndex.php>. Acesso em: 10 out. 2013.

COMITÊ DE PRONUNCIAMENTOS CONTÁBEIS. Pronunciamento Técnico CPC 19 (R1): negócio em conjunto. 2011. Disponível em: <http://www.cpc.org.br/pronunciamentosIndex.php>. Acesso em: 11 dez. 2013. 
COMITÊ DE PRONUNCIAMENTOS CONTÁBEIS. Pronunciamento Técnico CPC 19

(R2): negócio em conjunto. 2012. Disponível em: <http://www.cpc.org.br/pronunciamentosIndex.php>. Acesso em: 10 dez. 2013.

DARROUGH, M. N.; STOUGHTON, N. M. A bargaining approach to profit sharing in joint ventures. The Journal of Business, v. 62, n. 2, p. 237-270, 1989.

FIELDS, T. D.; LYS, T. Z.; VINCENT, L. Empirical research on accounting choice. Journal of Accounting and Economics, v. 31, p. 255-307, 1989, 2001.

FRANCIS, J. Discussion of empirical research on accounting choice. Journal of Accounting and Economics, v. 31, n. 1, p. 309-319, 2001.

FURUTA, F.; SANTOS, A. As exigibilidades nas demonstrações contábeis consolidadas de empresas com investimentos em joint ventures. In: ENCONTRO DA ANPAD, 30, 2006, Salvador. Anais... Salvador: ANPAD, 2006. Disponível em: <http://www.anpad.org.br/enanpad/2006/dwn/enanpad2006-fica-1346.pdF>. Acesso em: 01 dez. 2013.

GRAHAM, R. C.; KING, R. D.; MORRIL, C. K. J. Proportionate consolidation vs. the equity method: a decision usefulness perspective on reporting interests in joint ventures. Accounting Horizons, p.1-31, 2001.

GIL, A. C. Como elaborar projetos de pesquisa. 4. ed. São Paulo: Atlas, 2006.

GUJARATI, D. N. Basic econometrics. 4. ed. New York: McGraw-Hill, 2004.

HOSMER, D. W.; LEMESHOW, S. Applied Logistic Regression. 2. ed. New York: John Wiley \& Sons, 2000.

IUDÍCIBUS, S.; MARTINS, E.; GELBCKE, E. R.; SANTOS, A. Manual de contabilidade societária: aplicável a todas as sociedades de acordo com as normas internacionais e do CPC. São Paulo: Atlas, 2010.

JAAFAR, A.; MCLEAY, S. Country Effects and Sector Effects on the Harmonization of Accounting Policy Choice. ABACUS, v. 43, n. 2, 2007.

JOHNSTON, J.; DINARDO, J. Métodos econométricos. 4. ed. Lisboa: McGraw Hill, 2001.

LO, K. Earnings management and earnings quality. Journal of Accounting and Economics, v. 45, n. 2-3, p. 350-357, 2008.

LOPES, A. B.; IUDÍCIBUS, S. Teoria avançada da contabilidade. São Paulo: Atlas, 2004.

LORENCINI, F. D.; COSTA, F. M. Escolhas Contábeis no Brasil: identificação das características das companhias que optaram pela manutenção versus baixa dos saldos do ativo diferido. Revista Contabilidade e Finanças, v. 23, n. 58, p. 52-64, 2012.

LOURENÇO, I. C.; CURTO, J. D. Determinants of the accounting choice between alternative reporting methods for interests in jointly controlled entities. European Accounting Review, v. 19, n. 4, p. 739-773, 2010.

MACHADO, I. M. Consolidação proporcional das demonstrações contábeis de empresas controladas em conjunto (joint-ventures): a eficácia de suas informações no processo de tomada de decisão. CVM, 2011. Disponível em: $<$ http://www.cvm.gov.br/port/snc/T\%F3pico\%2017\%20-Consolida\%E7\%E3o\%20-

R. Cont. Ufba, Salvador-Ba, v. 9, n. 2, p. 52 - 67, mai-ago 2015 
\%20Anexo\%20III\%20-\%20Artigo\%20de\%20Itamar\%20Miranda\%20Machado.pdf >. Acesso em: 05 dez. 2013.

MACKENZIE, B.; COETSE, D.; NJIKIZANA, T.; CHAMBOKO, R.; COLYVAS, B.; HANEKOM, B. IFRS 2012: interpretação e aplicação. Porto Alegre: Bookman, 2013.

PENG, S.; SMITH, J. V. D. A. Chinese GAAP and IFRS: An analysis of the convergence process. Journal of International Accounting, Auditing and Taxation, v. 19, p. 16-34, 2010.

RICHARDSON, A. W.; ROUBI, R. R.; SOONAWALLA, K. Decline in financial reporting choice. European Accounting Review, v. 21, n. 2, p. 373-393, 2012.

TUDOR, A. T.; DRAGU, I. M. Impact of International Financial Reporting Standards on Accounting Practices Harmonization within European Union - Particular Case of Intangible Assets. AnnalesUniversitatis Apulensis Series Oeconomica, v. 12, n. 1, p. 191-206, 2010.

WATTS, R. L. Accounting choice theory and market-based research in accounting. British Accounting Review, v. 24, p. 235-267, 1992.

\section{APÊNDICE A: Companhias abertas selecionadas para a pesquisa}

\begin{tabular}{|c|c|c|c|}
\hline 1 & $\begin{array}{l}\text { AMÉRICA LATINA LOGÍSTICA MALHA } \\
\text { NORTE S.A. }\end{array}$ & 43 & LIGHT S.A. \\
\hline 2 & $\begin{array}{l}\text { AMÉRICA LATINA LOGÍSTICA MALHA } \\
\text { PAULISTA S.A. }\end{array}$ & 44 & LITEL PARTICIPAÇÕES S.A. \\
\hline 3 & AMERICA LATINA LOGÍSTICA S.A. & 45 & $\begin{array}{l}\text { LOG-IN LOGISTICA INTERMODAL } \\
\text { S.A. }\end{array}$ \\
\hline 4 & ALTUS SISTEMA DE AUTOMAÇÃO S.A. & 46 & $\begin{array}{l}\text { LPS BRASIL CONSULTORIA DE } \\
\text { IMÓVEIS S.A. }\end{array}$ \\
\hline 5 & ALUPAR INVESTIMENTO S/A & 47 & LUPATECH S.A. \\
\hline 6 & ANDRADE GUTIERREZ CONCESSÕES S.A. & 48 & $\begin{array}{l}\text { M. DIAS BRANCO S.A. IND COM DE } \\
\text { ALIMENTOS }\end{array}$ \\
\hline 7 & AREZZO INDÚSTRIA E COMÉRCIO S.A. & 49 & MAGAZINE LUIZA S.A. \\
\hline 8 & AUTOMETAL S.A. & 50 & MAGNESITA REFRATARIOS S.A. \\
\hline 9 & B2W COMPANHIA DIGITAL & 51 & MAHLE-METAL LEVE S.A. \\
\hline 10 & BHG S.A. BRAZIL HOSPITALITY GROUP & 52 & MARCOPOLO S.A. \\
\hline 11 & BRASKEM S.A. & 53 & MARFRIG ALIMENTOS S/A \\
\hline 12 & BROOKFIELD INCORPORAÇÕES S.A. & 54 & METALFRIO SOLUTIONS S.A. \\
\hline 13 & CCR S.A. & 55 & METALURGICA GERDAU S.A. \\
\hline 14 & CENTRAIS ELET BRAS S.A. & 56 & MINERVA S.A. \\
\hline 15 & CENTRAIS ELET DE SANTA CATARINA S.A. & 57 & $\begin{array}{l}\text { MRV ENGENHARIA E } \\
\text { PARTICIPAÇÕES S.A. }\end{array}$ \\
\hline 16 & CIA BRASILEIRA DE DISTRIBUIÇÃO & 58 & MULTIPLUS S.A. \\
\hline 17 & CIA ENERGÉTICA DE MINAS GERAIS & 59 & NATURA COSMÉTICOS S.A. \\
\hline 18 & CIA PARANAENSE DE ENERGIA & 60 & NEOENERGIA S.A. \\
\hline 19 & $\begin{array}{l}\text { CIA SANEAMENTO BÁSICO EST SAO } \\
\text { PAULO }\end{array}$ & 61 & OI S.A. \\
\hline 20 & CPFL ENERGIA S.A. & 62 & ÓLEO E GÁS PARTICIPAÇÕES S.A. \\
\hline 21 & $\begin{array}{l}\text { CIA TRANSMISSÃO ENERGIA ELÉTRICA } \\
\text { PAULISTA }\end{array}$ & 63 & $\begin{array}{l}\text { PDG REALTY S.A. EMPREEND E } \\
\text { PARTICIPAÇÕES }\end{array}$ \\
\hline
\end{tabular}

R. Cont. Ufba, Salvador-Ba, v. 9, n. 2, p. 52 - 67, mai-ago 2015 


\begin{tabular}{|l|l|r|l|}
\hline $\mathbf{2 2}$ & $\begin{array}{l}\text { CYRELA BRAZIL REALTY S.A.EMPREEND E } \\
\text { PART }\end{array}$ & $\mathbf{6 4}$ & POSITIVO INFORMÁTICA S.A. \\
\hline $\mathbf{2 3}$ & DALETH PARTICIPAÇÕES S.A. & $\mathbf{6 5}$ & PRUMO LOGÍSTICA S.A. \\
\hline $\mathbf{2 4}$ & DESENVIX ENERGIAS RENOVÁVEIS S.A. & $\mathbf{6 6}$ & $\begin{array}{l}\text { RODOBENS NEGÓCIOS } \\
\text { IMOBILIÁRIOS S.A. }\end{array}$ \\
\hline $\mathbf{2 5}$ & DIRECIONAL ENGENHARIA S.A. & $\mathbf{6 7}$ & ROSSI RESIDENCIAL S.A. \\
\hline $\mathbf{2 6}$ & EDP ENERGIAS DO BRASIL S.A. & $\mathbf{6 8}$ & $\begin{array}{l}\text { SARAIVA S.A. LIVREIROS } \\
\text { EDITORES }\end{array}$ \\
\hline $\mathbf{2 7}$ & EMBRAER S.A. & $\mathbf{6 9}$ & SUZANO PAPEL E CELULOSE S.A. \\
\hline $\mathbf{2 8}$ & ENEVA S.A & $\mathbf{7 0}$ & TECNISA S.A. \\
\hline $\mathbf{2 9}$ & EQUATORIAL ENERGIA S.A. & $\mathbf{7 1}$ & TEGMA GESTÃO LOGÍSTICA S.A. \\
\hline $\mathbf{3 0}$ & ETERNIT S.A. & $\mathbf{7 2}$ & TIM PARTICIPAÇÕES S.A. \\
\hline $\mathbf{3 1}$ & EVEN CONSTRUTORA E INCORPORADORA & $\mathbf{7 3}$ & TRIUNFO PARTICIP. E INVEST. S.A. \\
\hline $\mathbf{3 2}$ & S.A. & $\mathbf{7 4}$ & TRACTEBEL ENERGIA S.A. \\
\hline $\mathbf{3 3}$ & FLEURY S.A. & $\mathbf{7 5}$ & $\begin{array}{l}\text { TRANSMISSORA ALIANÇA DE } \\
\text { ENERGIA ELÉTRICA S.A. }\end{array}$ \\
\hline $\mathbf{3 4}$ & GAFISA S.A. & $\mathbf{7 6}$ & TRISUL S.A. \\
\hline $\mathbf{3 5}$ & GERDAU S.A. & $\mathbf{7 7}$ & UPTICK PARTICIPAÇÕES S.A. \\
\hline $\mathbf{3 6}$ & IDEIASNET S.A. & $\mathbf{7 8}$ & USINAS SID DE MINAS GERAIS S.A. \\
\hline $\mathbf{3 7}$ & INEPAR S.A. INDÚSTRIA E CONSTRUÇÕES & $\mathbf{7 9}$ & VALE S.A. \\
\hline $\mathbf{3 8}$ & IOCHPE MAXION S.A. & $\mathbf{8 0}$ & VALID SOLUÇÕES E SERV. SEG. \\
\hline $\mathbf{3 9}$ & JBS S.A. & $\mathbf{8 1}$ & VIA VAREJO PAG. IDENT. S.A.. \\
\hline $\mathbf{4 0}$ & JHSF PARTICIPAÇÕES S.A. & $\mathbf{8 2}$ & VIGOR ALIMENTOS S.A. \\
\hline $\mathbf{4 1}$ & JSL S.A. & $\mathbf{8 3}$ & VIVER INCORPORADORA E \\
\hline $\mathbf{4 2}$ & KLABIN S.A. & & \\
\hline & & \\
\hline
\end{tabular}

R. Cont. Ufba, Salvador-Ba, v. 9, n. 2, p. 52 - 67, mai-ago 2015 